\title{
Elucidating the Role of Anthropogenic Aerosols in Arctic Sea Ice Variations ${ }^{\mathscr{O}}$
}

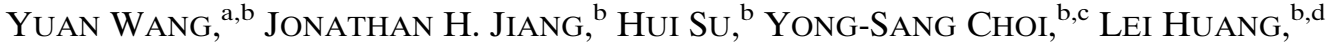 \\ JIANPING GUO, ${ }^{\mathrm{e}}$ AND YUK L. YUNG ${ }^{\mathrm{a}, \mathrm{b}}$ \\ a Division of Geological and Planetary Sciences, California Institute of Technology, Pasadena, California \\ ${ }^{\mathrm{b}}$ Jet Propulsion Laboratory, California Institute of Technology, Pasadena, California \\ ${ }^{\mathrm{c}}$ Department of Environmental Science and Engineering, Ewha Womans University, Seoul, South Korea \\ ${ }^{\mathrm{d}}$ Joint Institute for Regional Earth System Science and Engineering, University of California, Los Angeles, \\ Los Angeles, California \\ ${ }^{\mathrm{e}}$ State Key Laboratory of Severe Weather, Chinese Academy of Meteorological Sciences, Beijing, China
}

(Manuscript received 1 May 2017, in final form 20 September 2017)

\begin{abstract}
Observations show that the Arctic sea ice cover has been shrinking at an unprecedented rate since the 1970s. Even though the accumulation of greenhouse gases in the atmosphere has been closely linked with the loss of Arctic sea ice, the role of atmospheric aerosols in past and future Arctic climate change remains elusive. Using a state-of-the-art fully coupled climate model, the authors assess the equilibrium responses of the Arctic sea ice to the different aerosol emission scenarios and investigate the pathways by which aerosols impose their influence in the Arctic. These sensitivity experiments show that the impacts of aerosol perturbations on the pace of sea ice melt effectively modulate the ocean circulation and atmospheric feedbacks. Because of the contrasting evolutions of particulate pollution in the developed and developing countries since the 1970s, the opposite aerosol forcings from different midlatitude regions are nearly canceled out in the Arctic during the boreal summer, resulting in a muted aerosol effect on the recent sea ice changes. Consequently, the greenhouse forcing alone can largely explain the observed Arctic sea ice loss up to the present. In the next few decades, the projected alleviation of particulate pollution in the Northern Hemisphere can contribute up to $20 \%$ of the total Arctic sea ice loss and $0.7^{\circ} \mathrm{C}$ surface warming over the Arctic. The authors' model simulations further show that aerosol microphysical effects on the Arctic clouds are the major component in the total aerosol radiative forcing over the Arctic. Compared to the aerosol-induced energy imbalance in lower latitudes outside the Arctic, the local radiative forcing by aerosol variations within the Arctic, due to either local emissions or long-range transports, is more efficient in determining the sea ice changes and Arctic climate change.
\end{abstract}

\section{Introduction}

As a strong climate feedback, the Arctic sea ice melt under global warming (Serreze et al. 2007; Comiso et al. 2008) plays a pivotal role in amplifying temperature increases in the high latitudes (Holland and Bitz 2003; Screen and Simmonds 2010) and therefore drastically alters the global energy balance, general circulation, and even midlatitude weather systems (Cohen et al. 2014). The long-term variations of the coupled atmosphere, sea ice, and ocean in the Arctic climate system are subject to

Supplemental information related to this paper is available at the Journals Online website: https://doi.org/10.1175/JCLI-D-170287.s1.

Corresponding author: Yuan Wang, yuan.wang@caltech.edu the influence from external forcings such as man-made greenhouse gases (GHG) (Notz and Stroeve 2016) and aerosols (Najafi et al. 2015), as well as natural variability (Ding et al. 2017) such as the Pacific decadal oscillation (PDO) (Screen and Francis 2016), Arctic Oscillation (Rigor et al. 2002), and even Earth orbital variations (Lee et al. 2017). In addition to energy perturbations from lower latitudes (Alexeev et al. 2005), radiative forcing of aerosols in the Arctic, especially their interactions with the polar mixed-phase clouds (Garrett et al. 2009; Zhao and Garrett 2015; Fan et al. 2016), could be crucial in regulating the magnitude and timing of sea ice melt. Recent in situ and spaceborne measurements revealed frequent Arctic haze formation from local sources (e.g., shipping, wild fires, industrial activities, and residential combustion) or transported from midlatitude regions (Arnold et al. 2016), which 


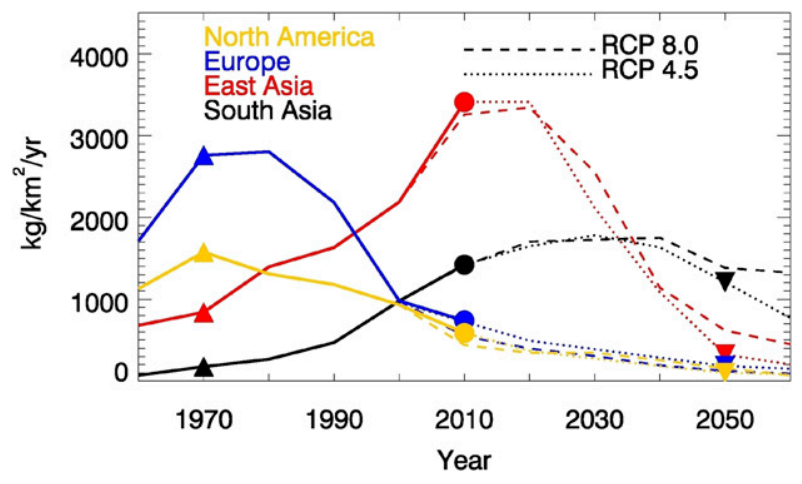

FIG. 1. Past and future anthropogenic sulfur dioxide emission changes over four different regions (East Asia, South Asia, Europe, and North America) from the IPCC AR5 emission dataset and RCP scenarios.

calls for a more quantitative assessment of the impacts of anthropogenic aerosols on Arctic sea ice and regional climate changes. Meanwhile, it is still an open question about the relative importance of the remote impacts from midlatitude aerosol variations compared to the local aerosol forcing in the Arctic (Kay et al. 2012; Sand et al. 2013a,b; Shindell and Faluvegi 2009).

One major challenge of quantifying the aerosol effects on Arctic sea ice arises from the large inhomogeneity of aerosol spatial distributions and temporal variations. A recent study using a climate model driven by transient forcings shows man-made aerosols could increase the Arctic sea ice over the middle of the twentieth century by providing a cooling effect (Gagné et al. 2017). From the 1970s to the present, the same time period when the severe Arctic sea ice loss occurred, the anthropogenic emission of aerosols and their precursor gases have been significantly reduced in Europe and North America as a result of the toughened air-quality regulations. In contrast, in the developing countries in East and South Asia, the anthropogenic emissions such as sulfur dioxide have increased by $4-5$ times because of industrialization and urbanization (Fig. 1). Therefore, the global pollution center has experienced a longitudinal shift in the Northern Hemisphere during the past four decades, which potentially influences the global energy budget and general circulation (Shindell and Faluvegi 2009; Wang et al. 2015). A recent study suggested that the European aerosol reduction alone could contribute to a $0.5^{\circ} \mathrm{C}$ increase in the Arctic surface temperature and up to a $10 \%$ decrease in the Arctic sea ice fraction (Navarro et al. 2016). The transient climate simulations using a climate model show a weak decrease of sea ice due to aerosol variations from 1975 to 2005 (Gagné et al. 2017). Therefore, a more comprehensive investigation is needed to understand the historical Arctic sea ice response to the recently redistributed aerosols by simultaneously considering the anthropogenic emission changes from different parts of the world. In the next 30-40 years until 2050, anthropogenic emissions in East Asia will likely drop to their 1970s level (Fig. 1). Along with the continuous emissions controls in the United States and Europe, the future aerosol reduction globally is expected to impose significant impacts on the Arctic sea ice melting (Gagné et al. 2015). Hence, climatemodeling assessments are also needed to quantify the possible influence of future anthropogenic aerosol variations on Arctic climate change.

Currently, there is a large spread of the sea ice simulations in the general circulation models (GCMs) from phase 5 of the Coupled Model Intercomparison Project (CMIP5) (Stroeve et al. 2012). Meanwhile, the sophistication of aerosol effects in different CMIP5 models, especially aerosol-cloud interactions, is also quite diverse, which can result in distinctive responses of the hydrological cycle to different magnitudes and distributions of aerosol forcings (Wang 2015). Those facts make it difficult to reveal the physics behind the complex aerosol influence on sea ice from the multimodel mean results. In this study, we employ one state-of-theart climate model with various idealized sensitivity experiments and ensemble simulations. The main objectives of this study are to disentangle the factors determining the magnitude and spatial pattern of sea ice changes under certain forcing and to quantify the historical and future impacts of anthropogenic aerosols with regionally different evolutions on the Arctic sea ice.

\section{Methods and data}

The NCAR-DOE Community Earth System Model, version 1.0.4 (CESM1), is used in this study to assess the equilibrium climatic response of the Arctic sea ice to various aerosol and greenhouse gas forcings. The sea ice model (CICE) fully interacts with an atmospheric circulation model (CAM5), an ocean circulation model (POP2), and a land surface model (CLM) through a central coupler. The latest version of CICE provides a complete treatment of sea ice dynamics, thermodynamics, and radiative transfer (Holland et al. 2012). Compared with other CMIP5 models, CESM1 historical simulations show good agreement with observed Arctic sea ice climatology and changes in recent decades (Fig. 2). Most of the observed annual mean sea ice fractions fall into the one standard deviation range of the CESM1 large-ensemble transient simulations from 1980 to 2005.

In our model setup, horizontal resolution is about $2^{\circ}$ in CAM5 and $1^{\circ}$ in POP2 and CICE. Six types of aerosols 


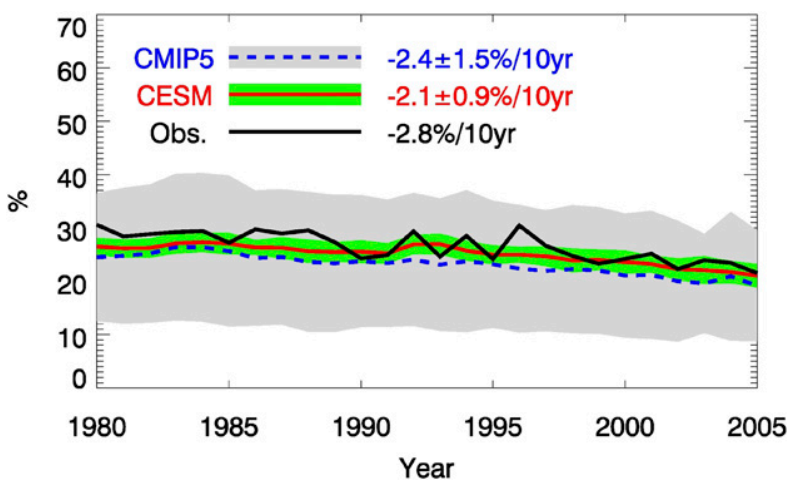

FIG. 2. Evolution of the Arctic sea ice fraction in September from observations (dark line), 24 CMIP5 models (blue dashed line for the multimodel mean, gray shading for the model spread), and NCAR CESM large ensemble simulations (red line for the multiensemble mean, green shading for the ensemble spread). Trends are calculated between 1980 and 2005. The period 1980-2005 is chosen because of the temporal overlap between reliable satellite measurements and the CMIP5 transient forcing dataset. The names of CMIP5 models used in this figure are listed in Table S1. Arctic sea ice fraction here is defined as the fraction of the region covered by sea ice within the Arctic $\left(65^{\circ}-90^{\circ} \mathrm{N}\right)$.

(sulfate, black carbon, primary organic matter, secondary organic aerosol, sea salt, and dust) are considered in the three-mode version of the Modal Aerosol Module (MAM3). Hygroscopicity characteristics are specified for each aerosol component, and the mass-weighted hygroscopicity of each size bin can be calculated for cloud condensation nuclei (CCN) activation. MAM3 provides internally mixed representations of number concentrations and mass for Aitkin, accumulation, and coarse aerosol modes. The aerosol module accounts for most of the important processes associated with atmospheric aerosols, including emission, nucleation, coagulation, condensational growth, gas- and aqueousphase chemistry, dry deposition, in-cloud and belowcloud scavenging, and reproduction from evaporated cloud droplets. The radiative effects of aerosols suspended in the atmosphere and the microphysical effects of cloud condensation nuclei and ice nuclei on the gridscale liquid/ice clouds are explicitly considered in the physical schemes in CAM5 (Liu et al. 2012; Wang et al. 2015, 2016). The radiative impacts of absorbing aerosols deposited in the snowpack or on the ice surface are also considered in CESM by coupling the Snow, Ice, and Aerosol Radiative (SNICAR) model (Flanner et al. 2007). The historical anthropogenic emissions of primary aerosols and precursor gases from 1850 to 2010 are adopted based on the IPCC AR5 emission dataset (Lamarque et al. 2010). Similar to the previous modeling studies that focused on future aerosol reduction (e.g., Rotstayn et al.2014), the future aerosol scenario is taken from the representative concentration pathway 4.5 (RCP4.5; Clarke et al. 2007). In fact, the projections of anthropogenic aerosol/precursor emissions do not differ significantly in different pathways, as shown in Fig. 1.

We perform climate simulations under different forcing scenarios (Table 1), and each scenario consists of three ensemble simulations with random perturbations exerted on the initial temperature fields. Our fully coupled CESM simulations start from the preindustry (PI) control conditions that had been integrated for 850 years. In each model simulation, only one type of forcing agent (either anthropogenic aerosols or greenhouse gases) is perturbed, and all other unperturbed forcers are fixed at the PI level. Such a setup lets the model reach a full equilibrium in a shorter time scale. We integrate CESM for another 130 years, and the results from the last 100 years will be used for analysis. The averaging over 100 years helps to smooth out the natural decadal variations and allows our study to concentrate on the forcing-response relationships. Several sensitivity experiments are designed to compare aerosol forcing during different periods with greenhouse gas forcing and to separately assess aerosol forcing from each individual region of our interest. Each experiment contrasts a pair of simulation sets, and each simulation set comprises three ensemble members. The details of the model runs and sensitivity experiments are listed in Tables 1 and 2. Two sets of slab ocean model simulations are performed with fixed ocean heat transports, and their comparisons with fully coupled simulations illustrate the influence of the modulated ocean dynamics. For the simulations excluding the anthropogenic aerosol variations within the Arctic (AERO_RCP noArctic), an aerosol nudging approach (Wang et al. 2017) is employed to fix the anthropogenic aerosol concentration over the Arctic at a constant climatological level.

To get an idea of relative strength of the Arctic aerosol forcing in CESM1 compared to the other CMIP5 models, we perform additional analyses on the CMIP5 historical simulations (Table S1 in the online supplemental material). The derived sea ice fraction trends (1939-70) under the anthropogenic aerosol forcing in the historical simulations shows that the elevation of anthropogenic aerosol concentrations during that period leads to an increase of Arctic sea ice by $+1.83 \%$ decade $^{-1}$ in CESM1. It is close to the upper bound of the CMIP5 mulitmodel range of $-0.9 \% \pm 1.4 \%$ decade $^{-1}$. Such a strong aerosol impact over the Arctic in CESM1 was also found in the aerosol-induced Arctic surface temperature trends in CMIP5 as reported by Fyfe et al. (2013), where CESM1 showed $-0.35 \mathrm{~K}$ decade $^{-1}$ while the multimodel range is $-0.15 \pm 0.2 \mathrm{~K} \mathrm{decade}^{-1}$ during $1939-70$.

The observed sea ice fraction over the Arctic is adopted from the National Snow and Ice Data Center 
TABLE 1. CESM simulations. For each model run, if not mentioned specifically in the table, all the emissions and atmospheric compositions are prescribed at the preindustrial level.

\begin{tabular}{|c|c|c|c|}
\hline Simulation name & Simulation description & $\begin{array}{c}\text { Integration } \\
\text { years }\end{array}$ & $\begin{array}{c}\text { Ensemble } \\
\text { runs }\end{array}$ \\
\hline AA1970 & Prescribing anthropogenic aerosol emissions at the year 1970 level & 130 & 3 \\
\hline AA2010 & Prescribing anthropogenic aerosol emissions at the year 2010 level & 130 & 3 \\
\hline AA2010_EU & $\begin{array}{l}\text { Prescribing anthropogenic aerosol emissions in Europe and the United States } \\
\text { at the year } 2010 \text { level, rest of the world at } 1970\end{array}$ & 130 & 3 \\
\hline AA2050 & Prescribing anthropogenic aerosol emissions at the year 2050 level & 130 & 3 \\
\hline GHG1970 & Prescribing GHG concentrations at the year 1970 level & 130 & 3 \\
\hline GHG2010 & Prescribing GHG concentrations at the year 2010 level & 130 & 3 \\
\hline AA2050_Nudge & $\begin{array}{l}\text { Same emissions as AA2050 but with nudging of Arctic aerosols at the } \\
\text { year } 2010 \text { level }\end{array}$ & 130 & 3 \\
\hline AA1970(SOM) & Same emissions as AA1970 but with slab ocean configuration & 50 & 5 \\
\hline AA2010(SOM) & Same emissions as AA2010 but with slab ocean configuration & 50 & 5 \\
\hline AA1970(CAM5) & Same emissions as AA1970 but with CAM5 only & 10 & 5 \\
\hline AA2010(CAM5) & Same emissions as AA2010 but with CAM5 only & 10 & 5 \\
\hline $\begin{array}{l}\text { AA2010_EU } \\
\text { (CAM5) }\end{array}$ & Same emissions as AA2010_EU but with CAM5 only & 10 & 5 \\
\hline
\end{tabular}

(NSIDC) gridded monthly sea ice extent and concentration, version 1.1 (Walsh et al. 2016). This dataset compiles observations from available historical sources of monthly sea ice concentration since 1850 , while only spaceborne passive microwave data is used after 1979.

\section{Results}

\section{a. Arctic sea ice responses under different forcing scenarios}

\section{1) FORCING PATTERNS}

The anthropogenic aerosol changes in different forcing experiments are displayed in Fig. 3. Following the evolutions of the anthropogenic aerosol and precursor gas emissions from 1970 to 2010, the longitudinal shift of the aerosol optical depth (AOD) pattern is evident in the Northern Hemisphere. If the anthropogenic aerosol emissions are fixed constant in all the regions except Europe and the United States in an idealized experiment (AERO_EU), the Arctic could experience even larger aerosol reductions since the 1970s. RCP4.5 shows us a belt of aerosol reduction regions in the midlatitudes of the Northern Hemisphere from 2010 to 2050, with the maximal reduction occurring over eastern China. An analysis of aerosol chemical composition (Fig. S1) shows the changes in aerosol concentrations from 1970 to 2050 are dominated by sulfate aerosols. Aerosols modulate Earth's climate mainly through alteration of the radiation fluxes in the atmosphere. The effective radiative forcing (ERF) is defined as the fast response of the topof-atmosphere net radiative flux to certain climate forcings with sea surface temperature unchanged. The ERF of the anthropogenic aerosol variations since the 1970s can be obtained from our atmosphere-only (CAM5) simulations, which exclude the slow responses from oceans and sea ice (Fig. 4a). As a result of

TABLE 2. Sensitivity experiment design.

\begin{tabular}{|c|c|c|}
\hline Experiment name & Experiment purpose & Realization \\
\hline AERO_GB & $\begin{array}{l}\text { To assess global anthropogenic aerosol effect between the } \\
\text { year } 1970 \text { and } 2010\end{array}$ & AA2010 - AA1970 \\
\hline AERO_EU & $\begin{array}{l}\text { To assess anthropogenic aerosol effect over Europe and the } \\
\text { United States between the year } 1970 \text { and } 2010\end{array}$ & AA2010_EU - AA1970 \\
\hline GHG & $\begin{array}{l}\text { To assess global greenhouse gas effect between the year } \\
1970 \text { and } 2010\end{array}$ & GHG2010 - GHG1970 \\
\hline AERO_RCP & $\begin{array}{l}\text { To assess global anthropogenic aerosol effect between the } \\
\text { year } 2010 \text { and } 2050 \text { following RCP } 4.5\end{array}$ & AA2050 - AA2010 \\
\hline AERO_RCP_noArctic & $\begin{array}{l}\text { To assess remote influence of anthropogenic aerosols outside } \\
\text { of the Arctic }\end{array}$ & AA2050_Nudge - AA2010 \\
\hline AERO_GB_SOM & To assess the impact of modulated ocean dynamics & AA2010(SOM) - AA1970(SOM) \\
\hline AERO_EU_CAM5 & To tease out ocean/sea ice feedbacks & AA2010_EU(CAM5) - AA1970(CAM5) \\
\hline
\end{tabular}



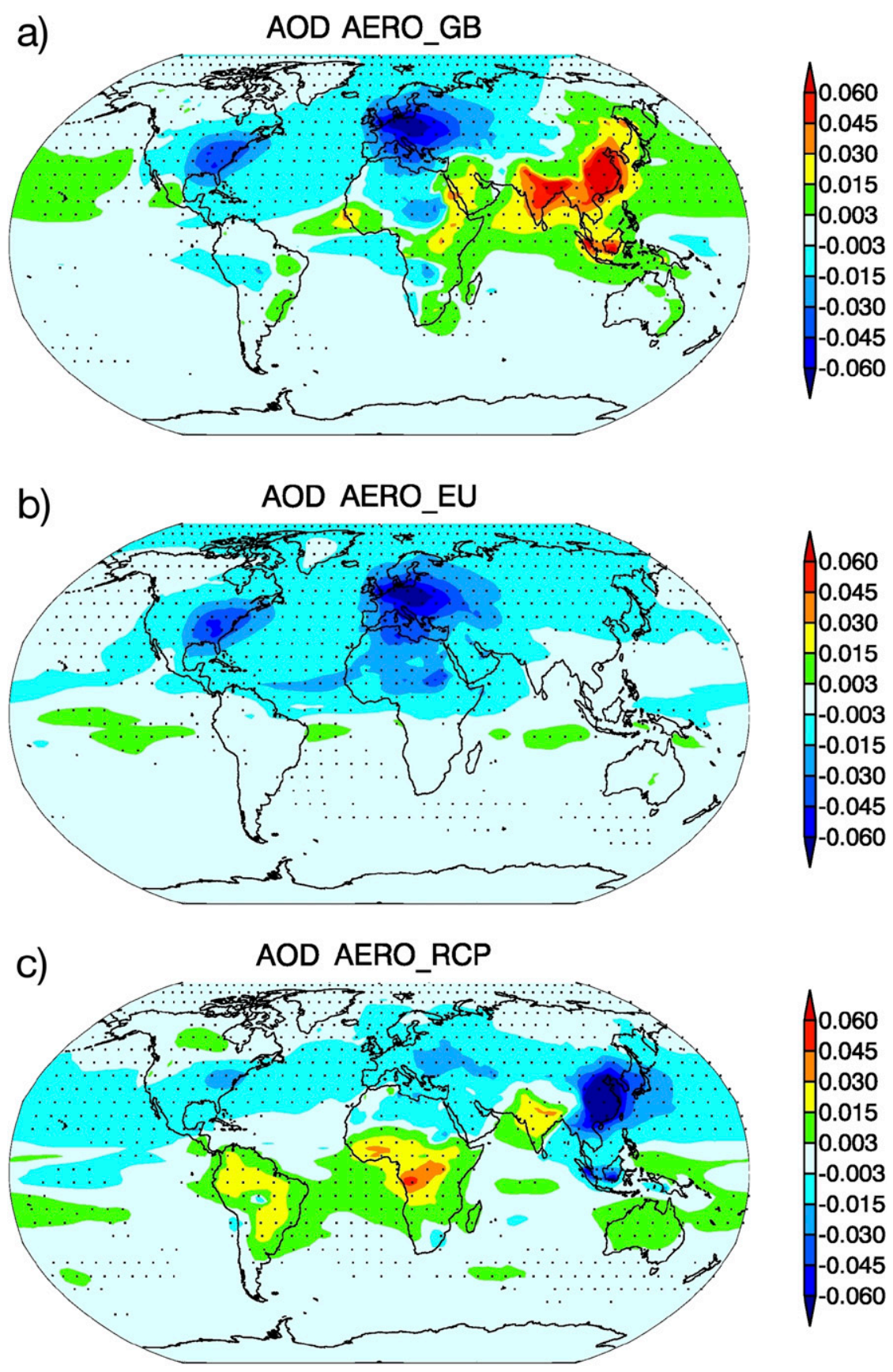

FIG. 3. CESM simulated difference in AOD in three scenarios of global anthropogenic aerosol emission changes: (a) global emission changes between 2010 and 1970, (b) Europe and U.S. emission changes between 2010 and 1970, and (c) global emission changes between 2050 and 2010.

the reduced aerosol concentrations in central Europe and the northwest United States, the decreased cloud reflectivity and weakened solar scattering induce a "dimming" effect and result in $5 \mathrm{~W} \mathrm{~m}^{-2} \mathrm{ERF}$ as a local maximum. Such a positive ERF extends from midlatitude Europe and the United States to the North
Atlantic and even the North Pole. Meanwhile, the exacerbating Asian pollution produced a negative ERF anomaly in the northeast part of the Eurasian continent. The net positive (negative) radiative forcing with a decrease (increase) in aerosol concentration reflects that the black carbon effect in the atmosphere, which is 

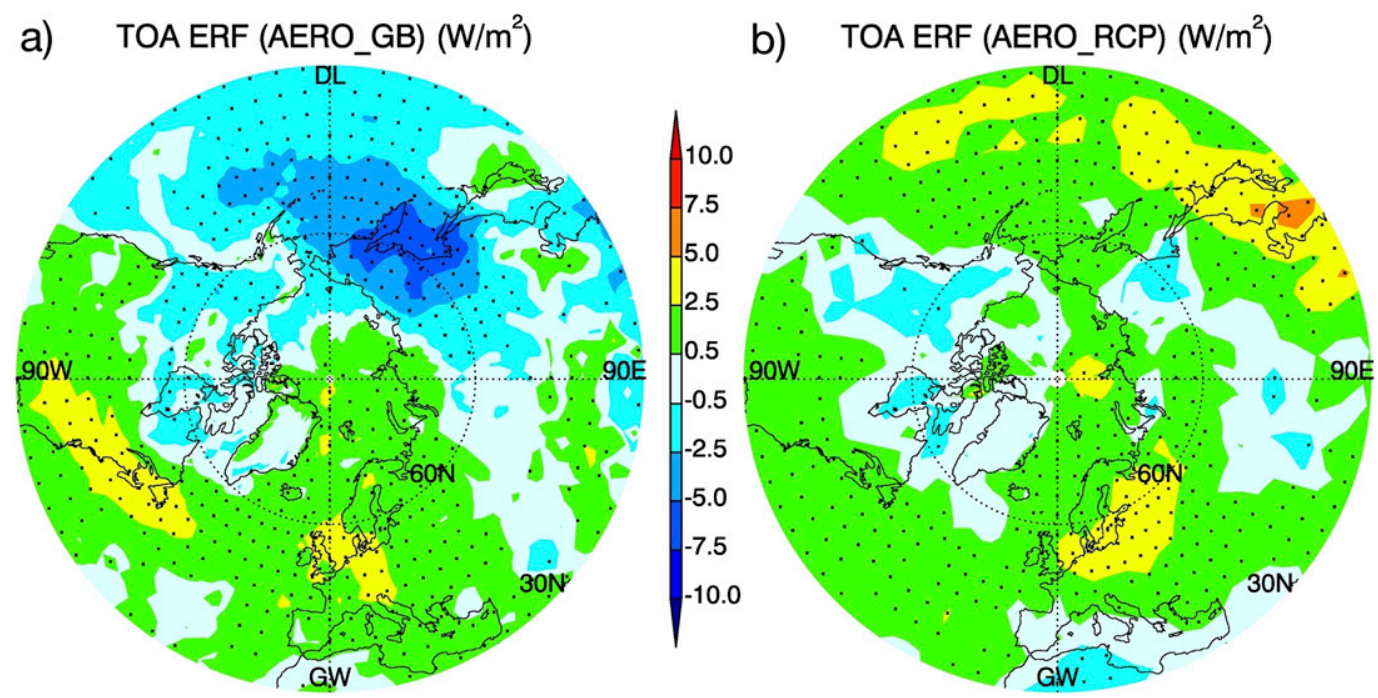

FIG. 4. (a) ERF at the top of atmosphere due to the global anthropogenic aerosol changes between the year 1970 and 2010 from an atmosphere-only global climate model. (b) As in (a), but due to the future anthropogenic aerosol changes in RCP4.5. ERF is defined as the rapid changes in net radiative flux at the top of atmosphere before sea surface temperature adjustment (Ghan et al. 2012).

supposed to induce a positive radiative forcing, is overshadowed by that of sulfate aerosols. In the Arctic, the ERF exhibits a "dipole" pattern that indicates the potential competition of different forcings in shaping the regional climate. However, such a scenario will not stand valid throughout the twenty-first century, as the global mean anthropogenic emission is projected to be gradually reduced, and air pollution in the developing countries is expected to be mitigated eventually in the future (Kirtman et al. 2013). All the RCP scenarios are consistent with such a projection. With that, the further aerosol reduction in Europe and stricter emissions controls in East Asia since the 2010s will induce 3-6 $\mathrm{W} \mathrm{m}^{-2}$ ERF regionally by 2050 , which unambiguously results in a net positive ERF on the Arctic (Fig. 4b).

\section{2) HistoricAl SEA ICE RESPONSES (1970-2010)}

The equilibrium responses of Arctic sea ice to different anthropogenic forcings are quantified in the model experiments. Under the influence of global aerosol changes from 1970 to 2010 (the AERO_GB experiment), the Arctic sea ice fraction change is small and insignificant throughout the year (Fig. 5a). The sea ice change in September is only $-0.4 \% \pm 0.5 \%$. The changes in each month are even indistinguishable from the model internal variability. Spatially, only the scattered regions near the Greenland Sea and northern Europe show slight decreases (less than 10\%) in September (Fig. 5b). Such an equilibrium response is consistent with the transient aerosol forcing simulation by Gagné et al. (2017), which reported Arctic sea ice extent
(SIE) increases and then decreases over the 1970-2010 period. The spatial pattern of sea ice changes in AERO_ GB does not follow the characteristic dipole pattern of aerosol ERF (Fig. 4a). Hence, there must be some buffering processes that mediate the forcing exerted on the Arctic ocean/ice surface. Deep ocean circulations are considered important in determining the spatial patterns of responses to different forcing on the global scale (Xie et al. 2013) and are demonstrated to be able to enhance the sea ice loss in a warming climate (Taylor et al. 2013).

To probe the role of ocean dynamics in the Arctic, another set of the AERO_GB experiments are performed by running the same climate model but without deep ocean circulations. To achieve this, we replace the multilayer deep ocean model (POP) with a one-thermallayer ocean model (SOM). In this slab ocean experiment (AERO_GB_SOM), we find vastly different sea ice responses compared to those in the fully coupled model (Fig. 6). As a result of the cooling effect from the elevation of the Asian anthropogenic aerosols, significant increases in sea ice fraction could occur over the whole Pacific part of the Arctic Ocean $\left(90^{\circ} \mathrm{E}-90^{\circ} \mathrm{W}\right)$, when ocean heat transport has no variations in response to the surface energy anomaly. Meanwhile, only a small region along the west coast of Greenland shows a decrease in the sea ice fraction under the influence of the aerosol decrease over Europe and the United States. Such a contrast between AERO_GB and AERO_GB_SOM justifies our hypothesis that ocean circulations play an important role in redistributing the surface energy 
a)

Sea Ice Fraction Change

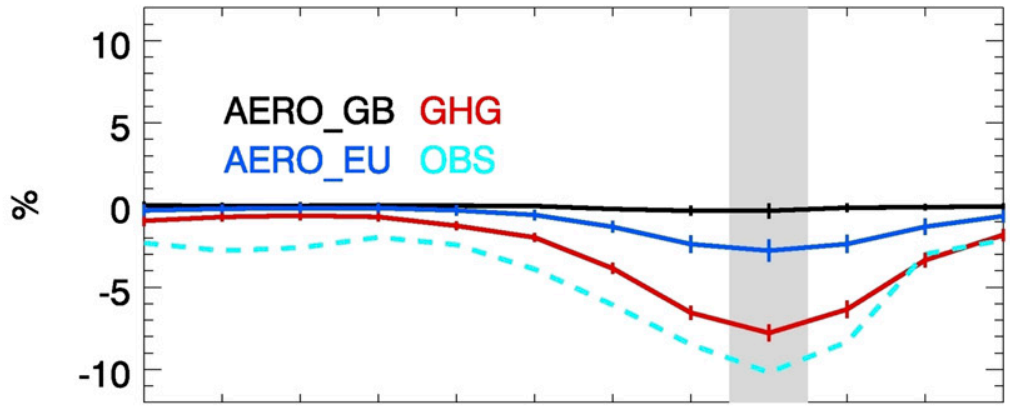

\section{$\begin{array}{llllllllllll}J & F & M & A & M & J & J & A & S & O & N & D\end{array}$ \\ Month}

b) PD-HD (AERO_GB) Diff. (\%)

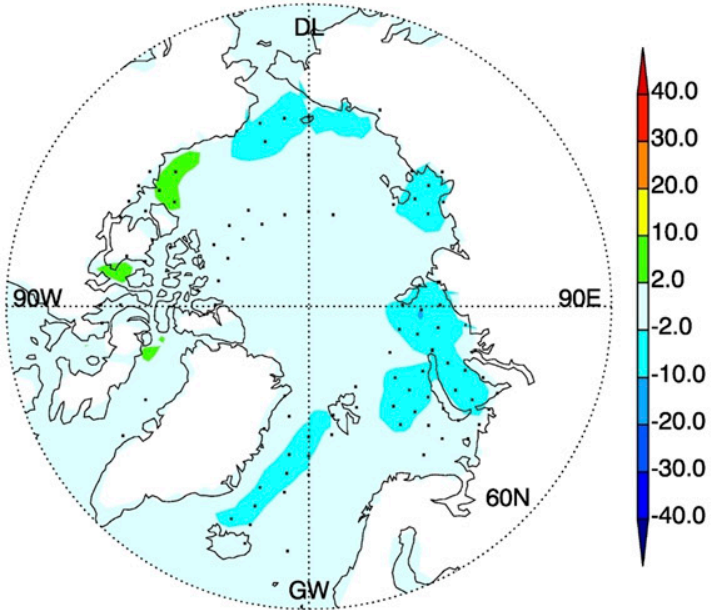

d) $\quad \mathrm{PD}-\mathrm{HD}(\mathrm{GHG})$ Diff. (\%)
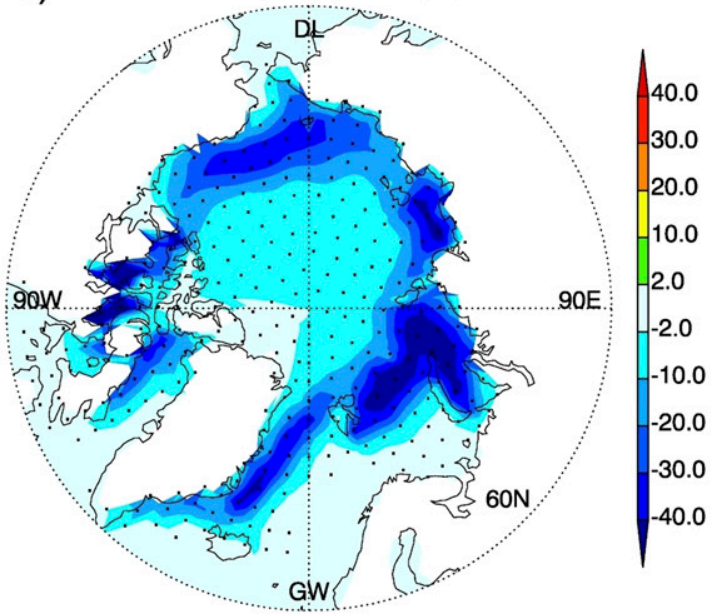

PD-HD (AERO_EU) Diff. (\%)

c)

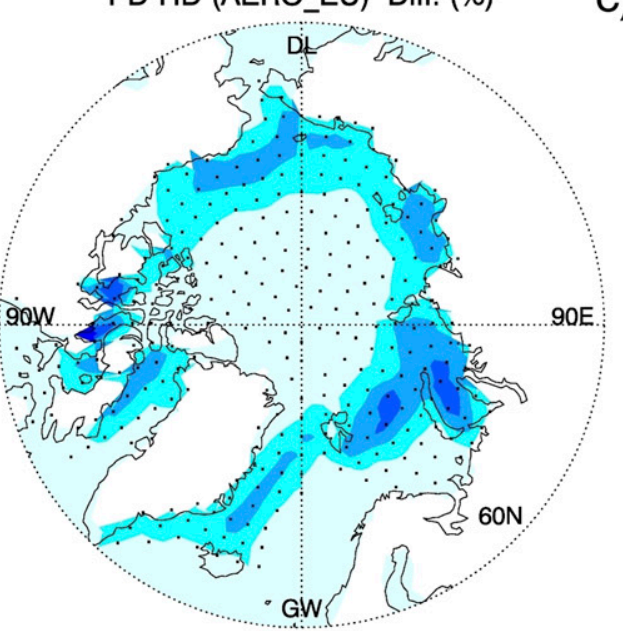

PD-HD (OBS) Diff. (\%)

e)

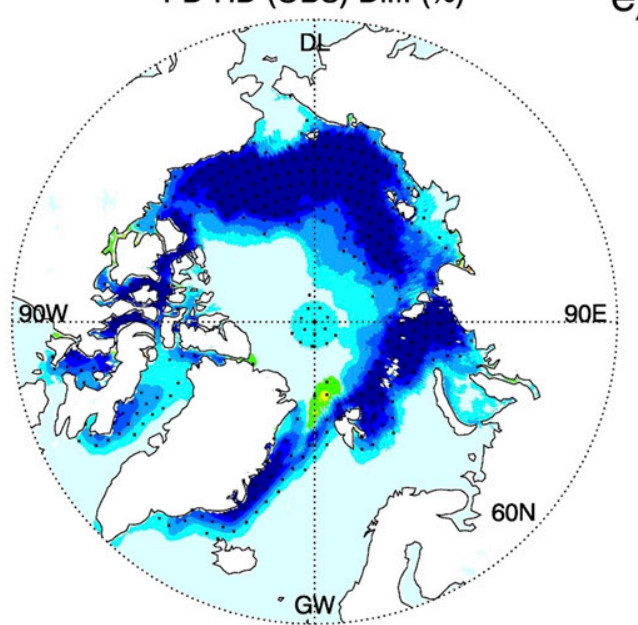

FIG. 5. The simulated Arctic sea ice fraction changes under different anthropogenic forcings from the 2010 to 1970 emission changes and the decadal differences of sea ice fraction from observations. (a) Seasonal cycles of simulated and observed sea ice fraction changes over the Arctic $\left(65^{\circ}-90^{\circ} \mathrm{N}\right)$. (b) Simulated sea ice change in September under AERO_GB. (c) Simulated sea ice change in September under AERO_EU. (d) Simulated sea ice change in September under GHG. (e) The observed differences of decadal mean sea ice fractions in September between 2004-13 and 1964-73. Error bars in (a) denote the spread of ensemble simulations. 


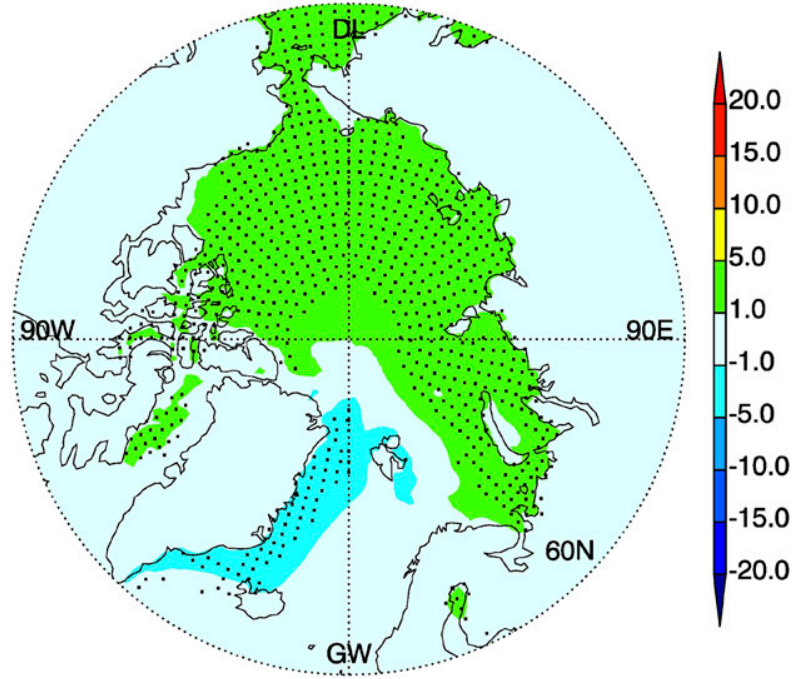

FIG. 6. Simulated Arctic sea ice fraction changes in AERO_GB with the slab ocean configuration of CESM.

anomaly, exchanging the heat between the Pacific and Atlantic sectors, and shaping the sea ice responses in the polar region. The active Arctic Ocean circulations beneath the floating sea ice and the efficient mixing of Pacific and Atlantic source waters have been documented by previous observations (e.g., Jones et al. 1998).

The separate contributions of particulate pollution to the Arctic sea ice change from the developed and developing countries can be identified through an additional idealized model setup in which only the aerosol reduction in Europe and the United States are considered (the AERO_EU experiment) with fixed emissions in other parts of the world. Consistent with a previous study (Navarro et al. 2016), the aerosol reduction in some developed countries could induce a substantial decline in sea ice concentration over most of the Arctic, especially along the ice edge with up to a $20 \%$ reduction in ice fraction (Fig. $5 \mathrm{c}$ ). The September sea ice change can be $-2.8 \% \pm 0.7 \%$. The distinctive responses from different emissions scenarios with and without the Asian pollution suggest that an increase in aerosol loading in East/South Asia and the corresponding cooling effect during the past four decades can largely offset the influence of the aerosol reduction in Europe and the United States on the Arctic sea ice. During the same time period, the carbon dioxide concentration has been increased by about $63 \mathrm{ppm}$ in the global mean. When we impose the total GHG changes alone from 1970 to 2010 (the GHG experiment), a much stronger sea ice decline is found $(-7.8 \% \pm 0.7 \%$ in September $)$. Such a melt is $\sim 3$ times greater than that due to an aerosol reduction in Europe/the United States and $\sim 20$ times greater than that caused by global aerosol changes during the same period (Fig. 5d). More important, the GHG-only simulation can largely reproduce the observed differences (Fig. 5e) of the decadal mean sea ice fraction between the years centering around 1970 and 2010 . These comparisons clearly demonstrate that the GHG forcing is one of the dominant factors in controlling the observed interdecadal changes in Arctic sea ice since the 1970s (Notz and Stroeve 2016), whereas the aerosol influence is largely muted as a consequence of the contrasting evolutions of anthropogenic emissions in the developed and developing countries. Note that even though our equilibrium experiment results are not directly comparable with the observed changes in the real world, the relative gaps between equilibrium responses under different forcings and observations can still tell us the relative importance of different forcings.

One interesting phenomenon is that Arctic sea ice changes show considerable resemblance in spatial and temporal patterns in both observations and model simulations, even the simulations with distinctive radiative forcings. Seasonally, both models and observations show the largest reduction of sea ice in September. Spatially, the maxima of the sea ice retreat always occur in the west of the Greenland Sea and over the shelves along the coast of the Eurasian continent, namely, the boundaries of the Arctic Ocean. These resemblances suggest how sensitive the sea ice extent is to the external forcings depends on the seasonality and location of the sea ice. Those are more relevant to the local sea ice dynamics and ocean circulations.

\section{3) FutURE SEA ICE RESPONSES (2010-50)}

Looking into the future, a nearly ice-free Arctic Ocean could be found in a summer of the twenty-first century (Overland and Wang 2013), but how early this would occur largely depends on the future radiative forcing changes. As predicted by the different RCP scenarios, the vast emissions decline in China after the year 2020 could be the most prominent feature in the global map of anthropogenic aerosol emissions, as we can see from the simulated global AOD changes between 2010 and 2050 in RCP4.5 (Fig. 3). Meanwhile, even though the magnitude of the continuing aerosol reductions in Europe and the United States will be much less than that in China, their influence cannot be overlooked, considering their shorter distance and more efficient transport pathways to the Arctic (Law et al. 2014). By taking the major aerosol reductions into account (AERO_RCP), the model shows a $7.1 \%$ fractional decrease in the September sea ice fraction over the Arctic from 2010 to 2050. Such a change is about one-fourth of the GHG-forcing-induced sea ice decline 


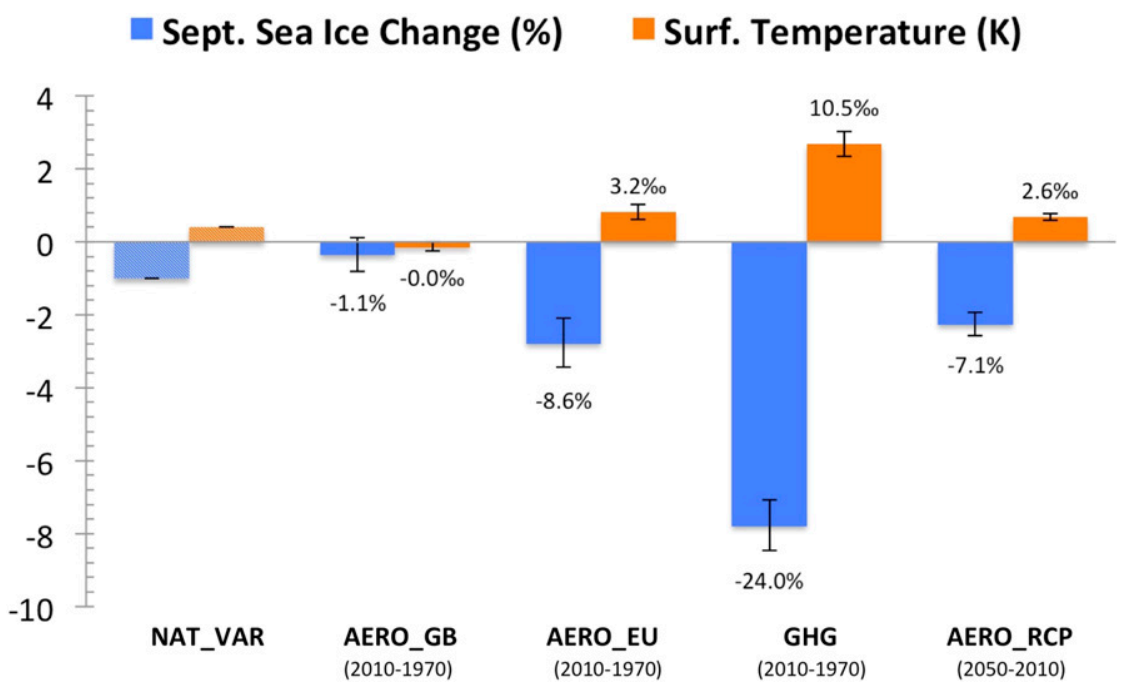

FIG. 7. Comparison of the simulated past and future September sea ice and annual mean surface temperature changes due to different forcings over the Arctic. The error bars are obtained from the different ensemble members. The numbers labeled above/below each color bar indicate the fractional changes (relative to control experiments) of each quantity. The natural variability (NAT_VAR) is the standard deviation of 100-yr results in one set of baseline simulations (AA1970).

from 1970 to 2010 . Hence, we can expect that the net aerosol effects will definitely imprint on the Arctic sea ice change. The future GHG concentration projections vary a lot across different RCPs. If we assume the GHG concentration will increase in a similar amount during the 40 years before and after 2010, like the RCP6.0 GHG emission scenario (Meinshausen et al. 2011), future aerosol reductions could contribute to about $20 \%$ of the total sea ice loss in the next three to four decades. Aerosols could make an even larger contribution if there would be less of a GHG increase such as in some RCP scenarios (e.g., RCP2.5) (Gagné et al. 2015). In addition, the future global pollution abatement can lead to a $0.7^{\circ} \mathrm{C}$ warming in the Arctic (Fig. 7) and $0.3^{\circ} \mathrm{C}$ in the global mean temperature (Fig. S2) based on our model equilibrium assessment.

\section{b. Pathway of aerosols to affect Arctic sea ice}

\section{1) DIFFERENT AEROSOL EFFECTS}

Theoretically, an equilibrium response of the Arctic climate is subject to the local radiative forcings, energy transport from outside of the Arctic, and the local feedback processes (i.e., surface albedo, surface latent heat fluxes, air temperature, and moisture content) (Taylor et al. 2013; Pithan and Mauritsen 2014). To understand the mechanisms driving the sea ice response to the redistributed aerosols from the 1970s to 2010s, it is therefore necessary to tease out the possible aerosol effects from a series of feedbacks. We decompose the Arctic surface radiation budget into clear sky and cloudy sky and longwave and shortwave fluxes, aiming to distinguish the aerosol direct and indirect effects as well as the ambient temperature/water vapor feedbacks. The radiative fluxes in AERO_GB and AERO_EU are compared, as their sea ice responses are quite different between those two sets of experiments. As a previous study suggested a precursory role of the summertime energy variation in determining sea ice changes (Choi et al. 2014), we focus on the summer months (JuneAugust) prior to the most significant sea ice response in September. As shown in Fig. 8a, the changes in clear-sky shortwave radiation reaching the surface are rather small in both AERO_GB and AERO_EU, indicating the pathway in which aerosols directly scatter/absorb the solar radiation is not important in perturbing the Arctic energy budget. This can be explained by the relatively low aerosol background concentration and low solar irradiance.

There are persistent mixed-phase clouds over the Arctic (Morrison et al. 2012), and satellite observations indicate the climatological cloud fraction can be as large as $90 \%$ especially over the region close to Europe (Wang et al. 2015). Also, there is the largest covariance between clouds and sea ice in fall (Taylor et al. 2015), which implies the potentially important influence of cloud adjustment under certain forcings. The aerosolinduced cloud radiative forcing in the AERO_EU 
a)

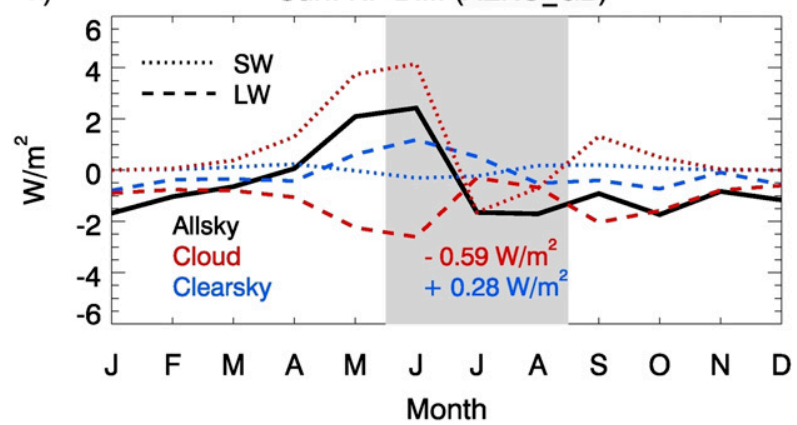

b)

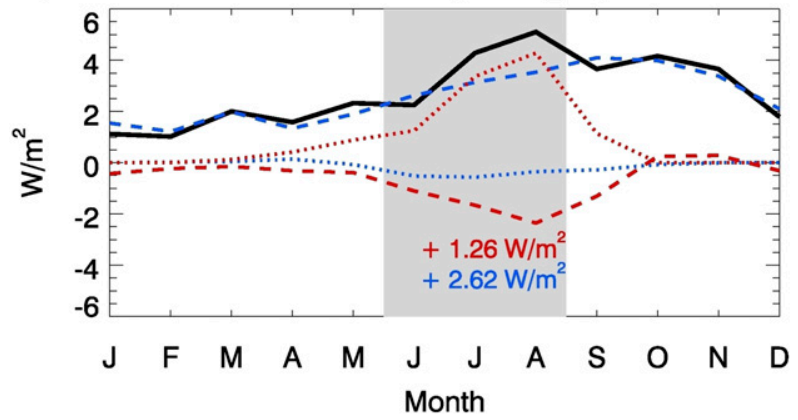

FIG. 8. The model-simulated difference in cloudy-sky, clear-sky, and all-sky radiative fluxes (RF) at the surface in (a) AERO_GB and (b) AERO_EU. To minimize the albedo feedbacks from the changing ocean/sea ice surface, we only consider downward radiative fluxes. Summertime (JJA) is shaded. Summer mean values of flux changes are labeled for cloudy (red) and clear sky (blue).

experiment can be $+3.9 \mathrm{~W} \mathrm{~m}^{-2}$ in late summer. In contrast, AERO_GB shows some positive cloud radiative forcing in May and June, but it becomes negative in July and August, which results in a much smaller cloud radiative forcing $-0.3 \mathrm{~W} \mathrm{~m}^{-2}$ as a summertime mean. The different cloud properties between AERO_GB and AERO_EU in response to different aerosol perturbations are further illustrated in Fig. 9. Changes in cloud droplet concentrations can partly reflect aerosol variations in different seasons. AERO_GB has both ups and downs from spring to fall, while AERO_EU has one single dip with larger variation and a nadir in August. The simulated liquid water paths (LWP) closely follow such seasonal patterns in both experiments, indicating the classic aerosol second indirect effect, that is, a CCNinduced reduction of cloud droplet radius, inefficient drizzle formation, prolonged cloud lifetime, and enlarged cloud water content. Considering the relatively low background aerosol concentrations in the remote polar region (Hamilton et al. 2014), such a significant aerosol indirect forcing is consistent with the previous theoretical and observational studies suggesting the high (low) sensitivity of cloud albedo and microphysical properties in the clear (polluted) conditions in response to CCN perturbations (Carslaw et al. 2013; Rosenfeld et al. 2014).

Meanwhile, the model simulates enhanced (reduced) longwave warming effects from the Arctic clouds caused by an increase (decrease) in aerosol concentrations (Fig. 8). The magnitude of longwave cloud forcing is found to be about half of the shortwave forcing. Such a longwave cloud effect is consistent with the previously observed enhancement of cloud emissivity induced by aerosols from the Arctic surface measurements (Garrett and Zhao 2006; Lubin and Vogelmann 2006). Since the longwave cloud forcing has an opposite sign compared to its shortwave counterpart but with smaller magnitude, the overall aerosol-cloud interactions induce a cooling. Hence, a reduction of aerosols in AEOR_EU results in an overall warming (Fig. 8b).

The clear-sky longwave radiation is a major constituent in the Arctic surface radiation budget. In AERO_ $\mathrm{EU}$, it explains two-thirds of the total radiative forcing on the surface (Fig. 8b). The enhanced positive clear-sky longwave radiation with the aerosol reduction indicates the strong positive feedbacks from the increased air temperature and moisture content following the opened ocean surface and elevated upwelling latent heat fluxes with the sea ice melt. It will be discussed later if those feedbacks are triggered by local aerosol variations in the Arctic or transport of heat/moisture from lower latitudes where larger aerosol variations occur. In AERO_ $\mathrm{GB}$, the variations of clear-sky longwave radiation are quite small after July, mainly due to the muted sea ice changes in this experiment.

\section{2) Aerosol Forcings vs FEEDBACKS}

One outstanding question in equilibrium climate simulations is how to attribute the simulated cloud changes to direct interaction with aerosols or variations of the ambient conditions to form clouds, such as air temperature and moisture, following the aerosol perturbations. Again, we examine and compare the 2-m air temperature and column water vapor in AERO_GB and AERO_EU (Fig. 9). Both the temperature and moisture changes are more noticeable in AERO_EU than those in AERO_GB. AERO_EU has a peak temperature increase in October. Considering the sea ice fraction minimum occurs in September, this onemonth lag reveals that the 2-m temperature changes are mainly explained by the opened ocean surface and enhanced surface heat fluxes. Hence, the temperature changes cannot explain the cloud changes in August. Meanwhile, we notice that the variations of water vapor amount show good correlation with LWP in month-tomonth variations. To further rule out the possible 

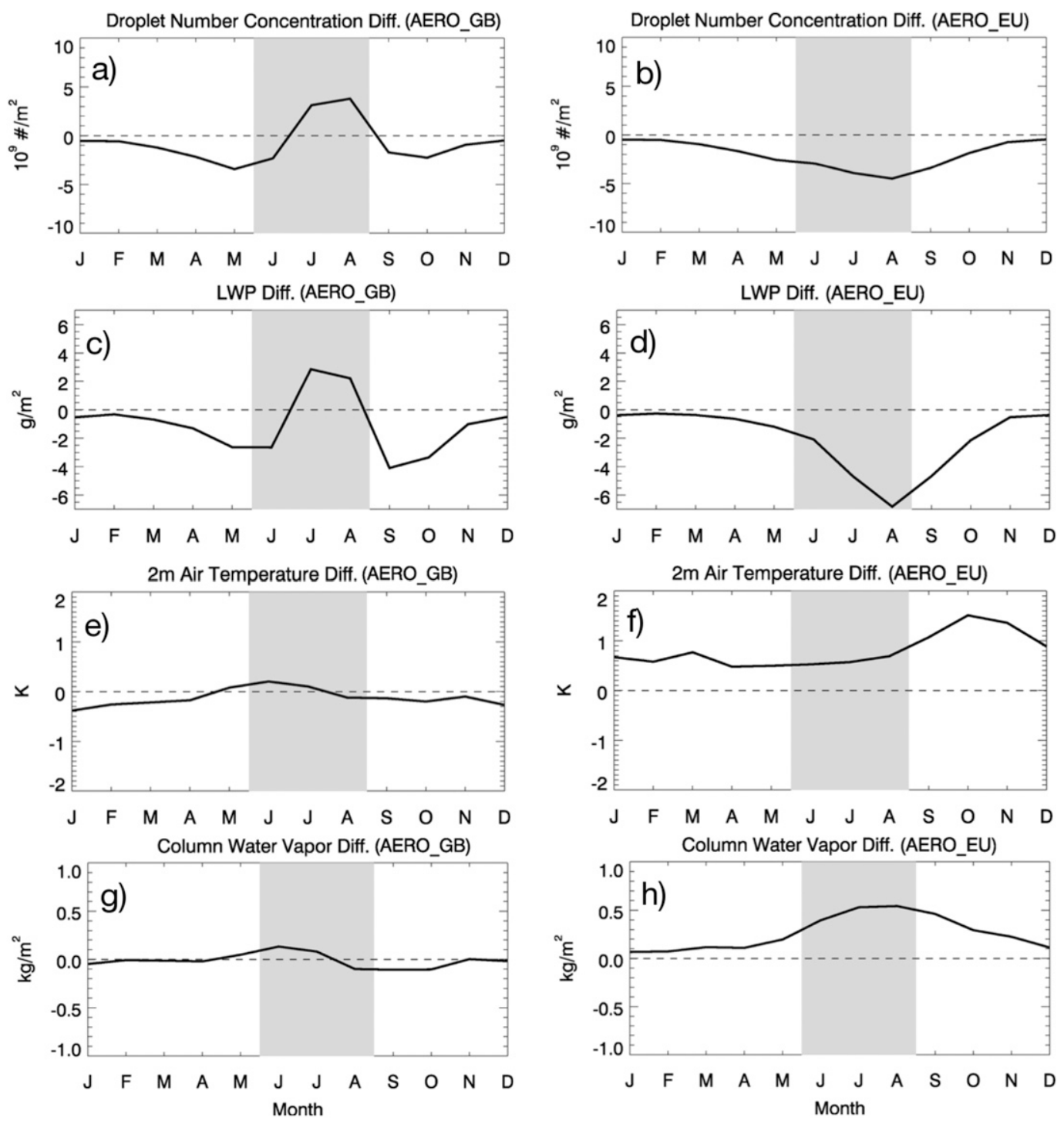

FIG. 9. Simulated atmospheric responses in AERO_GB and AERO_EU.

modulation of LWP by atmospheric water vapor as a feedback, we perform the AERO_EU experiments using the atmosphere-only version of CESM (i.e., CAM5). Since neither ocean nor sea ice responds to any atmospheric perturbations in this experiment, the Arctic atmospheric conditions, such as temperature and relative humidity, are not significantly changed in this experiment (Figs. 10a,b). Moreover, the liquid water content is still reduced by about $14 \%$ along with the reduction of aerosols from Europe and the United States by $25 \%$. This corroborates our previous hypothesis that only decreased $\mathrm{CCN}$ concentrations and enlarged cloud droplet effective radius can explain the reduction in cloud water amount (Fig. 9d) through the more efficient precipitation from the clouds, when the anthropogenic emissions are cut. Our sensitivity experiments and analysis above unambiguously demonstrate that the equilibrium cloud forcing changes in our experiments are mainly attributed to aerosol perturbations in the way of seeding clouds as condensation nuclei, rather than the feedbacks in the way of changes in ambient atmospheric temperature and humidity following the changes in the sea ice and ocean.

\section{3) Aerosol FORCINGS INSIDE AND OUTSIDE OF THE ARCTIC}

To investigate the relative importance of the aerosol forcings inside and outside of the Arctic, additional sensitivity experiments are performed that exclude the aerosol variations in the Arctic. The AERO_RCP_noArctic 

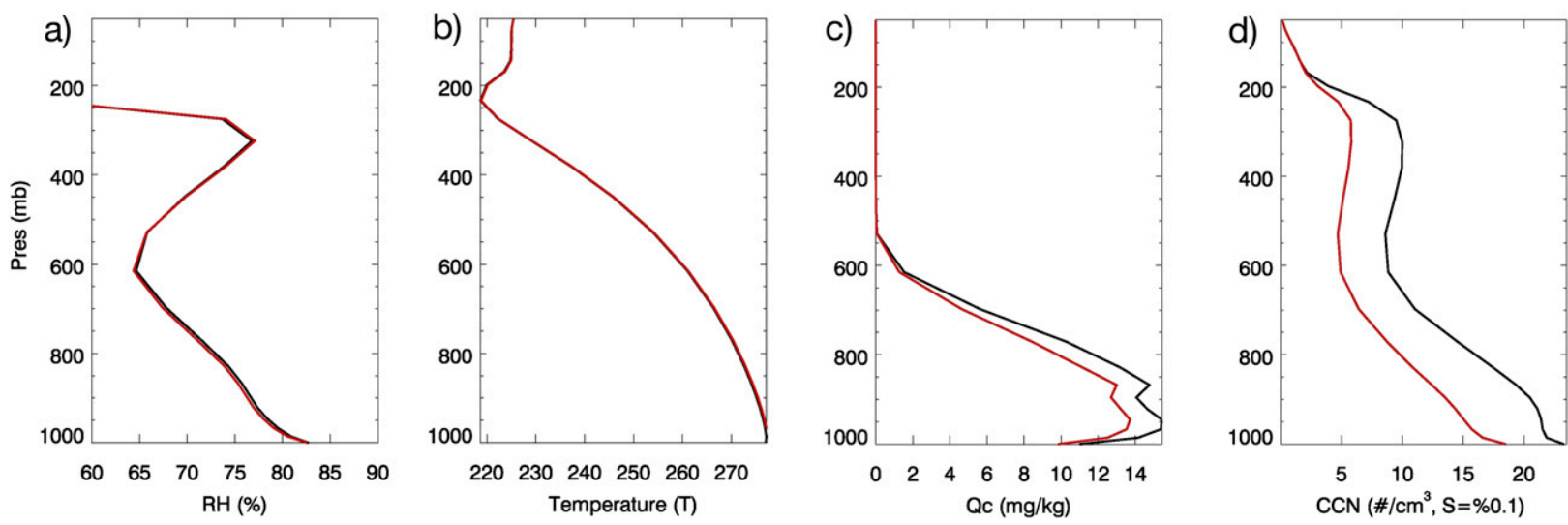

FIG. 10. CAM5 simulated atmospheric responses in AERO_EU. Qc stands for liquid water content. The red lines denote the simulations using the year 2010 anthropogenic aerosol/precursor gas emissions only over the United States and Europe, while the black lines denote the 1970 anthropogenic aerosol/precursor gas emission reconstruction.

experiment contrasts two sets of simulations. The baseline simulations are AA2010 with emissions of aerosols and precursor gases fixed at the year 2010 level. The sensitivity simulations AA2050_Nudge have 2050 anthropogenic aerosol emissions, but inside the Arctic, the six types of aerosol concentrations are nudged toward their climatology in AA2010. Therefore, the differences between AA2050 Nudge and AA2010 reflect aerosol changes outside of the Arctic from 2010 to 2050 and consequent poleward heat/ moisture transports.

As shown in Fig. 11, for the future emissions scenario, the absence of the aerosol reduction within the Arctic $\left(65^{\circ}-90^{\circ} \mathrm{N}\right)$ directly flips the sign of the aerosol effects on the sea ice concentration (Figs. 11c,d). When the reduction of aerosols only occurs over the midlatitudes, warm air advects to the Arctic mainly in the free troposphere, which stabilizes the upper part of the Arctic boundary layer (Fig. S3) and facilitates the Arctic low cloud formation (Herman and Goody 1976; Kay and Gettelman 2009). As a result, simulations show elevated cloud optical thickness, reduced shortwave radiation reaching the surface (Fig. S4), and anomalous cold surface air temperatures (Fig. 11f) over the Arctic during summer. Those further result in a significant increase in the sea ice fraction in September. In contrast, the aerosol reduction inside the Arctic and associated decrease in cloud optical thickness in AERO_RCP can mask out this teleconnection influence during summertime and result in more severe sea ice loss and warmer air temperatures in the fall season (Fig. 11e). The distinctive responses of the Arctic sea ice to the aerosols over different latitudinal regions suggest that the meridional transport of heat/moisture from lower latitudes is important for the Arctic climate (Kay et al. 2012; Shindell and Faluvegi 2009; Sand et al. 2015; Quinn et al.
2015), but the local forcing could play a more decisive role in determining the sea ice changes. This finding underscores the necessity to better represent aerosols in remote regions like the Arctic by accurately considering aerosol long-range transports and local emissions (Stohl et al. 2013). Similarly, Sand et al. (2015) also suggests the Arctic is more sensitive to aerosol emissions from Arctic nations, namely, a higher efficiency of local aerosol forcing, compared to the emissions and aerosol effect outside the Arctic.

\section{Conclusions and discussion}

By conducting fully coupled climate model simulations and comparing with long-term observations, we demonstrate the potential influence of anthropogenic aerosols on the Arctic sea ice and reveal the possible mechanisms of aerosol impacts. From the 1970s to the present, the increase in anthropogenic aerosols over East and South Asia and reduction in Europe and the United States battled over the Arctic, inducing a dipole pattern of the aerosol radiative forcing over the Arctic. Our climate model simulations show that the aerosols' fingerprints on the Arctic sea ice during this historical period were not discernible, with only $-0.4 \% \pm 0.5 \%$ ice fraction changes in September. In an idealized scenario, the Europe/U.S. emissions cut alone could melt a significant fraction of sea ice by about $-2.8 \% \pm 0.7 \%$. A much stronger sea ice decline is found $(-7.8 \% \pm 0.7 \%)$ under the scenario with only greenhouse gas forcing, which also well reproduces the observed sea ice loss in different decades. Those comparisons suggest the accumulation of GHGs is one of the dominant factors in controlling the observed interdecadal changes in the Arctic sea ice since the 1970s. Following RCP4.5, we 

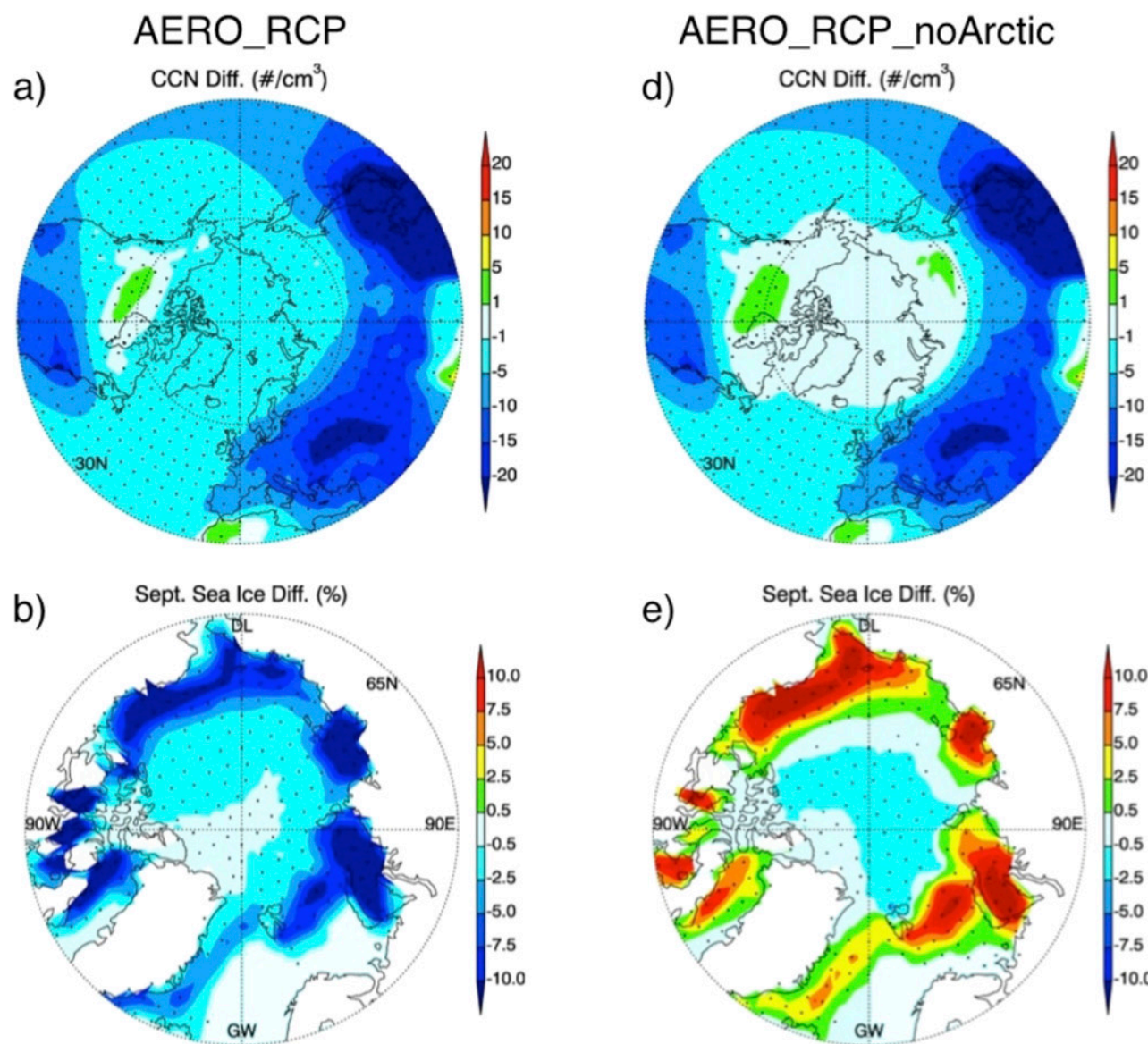

c)
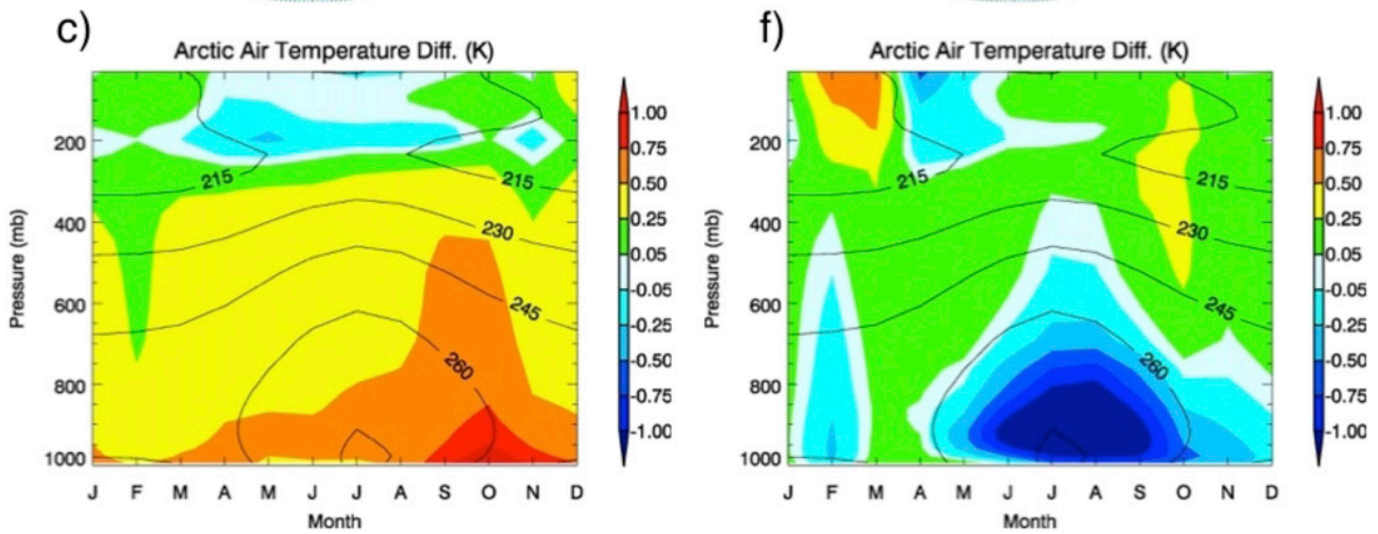

FIG. 11. Comparisons of the simulated changes in CCN concentrations, sea ice concentration, and Arctic air temperature $\left(65^{\circ}-90^{\circ} \mathrm{N}\right)$ due to different anthropogenic aerosol concentrations between 2010 and 2050 with (AERO_RCP) and without (AERO_RCP_noArctic) aerosol transport to the Arctic. The CCN concentrations at $0.1 \%$ supersaturation are averaged between 900 and $500 \mathrm{hPa}$.

estimate about a $7 \%$ fractional decrease in the Arctic sea ice due to the global anthropogenic aerosol reduction and associated $0.3^{\circ} \mathrm{C}$ warming globally, which roughly account for one-fourth of the GHG-induced sea ice and temperature changes in the Arctic. To avoid this deteriorating scenario before the middle of the twenty-first century and to meet the $1.5^{\circ} \mathrm{C}$ warming limit set by the
Paris Agreement, we need to put in a more concerted effort to reduce GHG emissions in the future.

A series of sensitivity experiments are conducted to shed light on the physical mechanisms of the aerosol effects and the efficiency of aerosol forcings over different regions. The boreal summertime net radiative forcing is found to be critical for the Arctic sea ice loss 
that peaks in September. The Arctic aerosol-cloud interactions largely determine the total radiative forcing by modulating cloud micro- and macrophysics such as cloud droplet radius and liquid water content, following the variations of aerosol concentrations in the Arctic. The ambient atmospheric temperature and humidity changes are also noticeable along with the sea ice melt. Sensitivity experiments further suggest that aerosol forcings within the Arctic as well as those imposed in the midlatitudes can cause Arctic sea ice changes, but the Arctic local aerosol forcing is more efficient in altering the sea ice fractions. Ocean circulations in the Arctic are important in regulating and redistributing the surface energy anomaly and in shaping the Arctic sea ice in response to external forcings.

We acknowledge that the assessments in this study are based on one climate model, and the robustness is subject to the uncertainties in the model physics. It has been found that CESM1 has relatively strong aerosol forcing in the Arctic compared to other CMIP5 models. It will be interesting to reevaluate the aerosol influence on the Arctic climate after the future release of the updated CMIP6 models. The relatively low Arctic aerosol concentrations in CAM5 due to the unrealistic heavy wet removal during the long-range transport (Wang et al. 2013) could make our assessed Arctic aerosol forcing biased toward the lower limit of its possible range. The Arctic liquid cloud fraction is found to be underestimated in CAM5 compared with satellite observations (Kay et al. 2016), while its possible impacts on aerosol forcing remain to be explored. The effect of absorbing aerosols on surface albedo after their deposition on the sea snow/ice is considered in our simulations but not isolated from other aerosol effects. Our present simulations imply a stronger impact of the scattering aerosols than the absorbing ones, as reductions of both absorbing and scattering aerosols result in a net positive radiative forcing. However, previous modeling assessments by Sand et al. (2015) and the Arctic Monitoring and Assessment Programme Report (Quinn et al. 2015) suggest nonnegligible warming effects from black carbon and ozone in the Arctic, especially black carbon deposited in snow. In particular, Sand et al. (2015) reported a reduction of $0.37 \mathrm{~K}$ warming between 2015 and 2050 in the Arctic due to the recently proposed global mitigation scenario (MIT) for short-lived climate warming forcers. Future works will include experiments that neglect black carbon/ dust deposition on snow to provide a detailed investigation of the aerosol albedo effect mechanism and a quantitative assessment of its climate impacts. The forcing efficiency of aerosol transports at different levels into the Arctic will be also explored by some idealized GCM simulations in our future work.
Acknowledgments. The authors appreciate the funding support by the NASA ROSES14-ACMAP project (NNH14ZDA001N-ACMAP). The research was primarily carried out at the Jet Propulsion Laboratory, California Institute of Technology, under a contract with the National Aeronautics and Space Administration. Y.-S. Choi is supported by the Korea Ministry of Environment (MOE) under the Public Technology Program based on Environmental Policy (2017000160003). Y. L. Yung received support from the NSF Division of Atmospheric and Geospace Sciences (1700727). All model results are stored at a JPL cluster and available upon request. Please contact Yuan Wang (yuan.wang@caltech. edu) to access the modeling data. The transient simulations from the CESM Large Ensemble Community Project are publicly available (http://www.cesm.ucar.edu/ projects/community-projects/LENS/).

\section{REFERENCES}

Alexeev, V. A., P. L. Langen, and J. R. Bates, 2005: Polar amplification of surface warming on an aquaplanet in "ghost forcing" experiments without sea ice feedbacks. Climate Dyn., 24, 655-666, doi:10.1007/s00382-005-0018-3.

Arnold, S. R., and Coauthors, 2016: Arctic air pollution: Challenges and opportunities for the next decade. Elementa Sci. Anthropocene, 4, 104, https://doi.org/10.12952/journal.elementa.000104.

Carslaw, K. S., and Coauthors, 2013: Large contribution of natural aerosols to uncertainty in indirect forcing. Nature, 503, 67-71, doi:10.1038/nature12674.

Choi, Y.-S., B.-M. Kim, S.-K. Hur, S.-J. Kim, J.-H. Kim, and C.-H. Ho, 2014: Connecting early summer cloud-controlled sunlight and late summer sea ice in the Arctic. J. Geophys. Res. Atmos., 119, 11 087-11 099, doi:10.1002/2014jd022013.

Clarke, L., J. Edmonds, H. Jacoby, H. Pitcher, J. Reilly, and R. Richels, 2007: Scenarios of greenhouse gas emissions and atmospheric concentrations. U.S. Climate Change Science Program Synthesis and Assessment Product 2.1, 155 pp., https:// science.energy.gov/ /media/ber/pdf/Sap_2_1a_final_all.pdf.

Cohen, J., and Coauthors, 2014: Recent Arctic amplification and extreme mid-latitude weather. Nat. Geosci., 7, 627-637, doi:10.1038/ngeo2234.

Comiso, J. C., C. L. Parkinson, R. Gersten, and L. Stock, 2008: Accelerated decline in the Arctic sea ice cover. Geophys. Res. Lett., 35, L01703, doi:10.1029/2007GL031972.

Ding, Q. H., and Coauthors, 2017: Influence of high-latitude atmospheric circulation changes on summertime Arctic sea ice. Nat. Climate Change, 7, 289-295, doi:10.1038/nclimate3241.

Fan, J., Y. Wang, D. Rosenfeld, and X. Liu, 2016: Review of aerosol-cloud interactions: Mechanisms, significance, and challenges. J. Atmos. Sci., 73, 4221-4252, doi:10.1175/ JAS-D-16-0037.1.

Flanner, M. G., C. S. Zender, J. T. Randerson, and P. J. Rasch, 2007: Present-day climate forcing and response from black carbon in snow. J. Geophys. Res., 112, D11202, doi:10.1029/ 2006JD008003.

Fyfe, J. C., K. von Salzen, N. P. Gillett, V. K. Arora, G. M. Flato, and J. R. McConnell, 2013: One hundred years of Arctic surface temperature variation due to anthropogenic influence. Sci. Rep., 3, 2645, doi:10.1038/srep02645. 
Gagné, M. È., N. P. Gillett, and J. C. Fyfe, 2015: Impact of aerosol emission controls on future Arctic sea ice cover. Geophys. Res. Lett., 42, 8481-8488, doi:10.1002/2015GL065504.

_ J. C. Fyfe, N. P. Gillett, I. V. Polyakov, and G. M. Flato, 2017: Aerosol-driven increase in Arctic sea ice over the middle of the 20th century. Geophys. Res. Lett., 44, 7338-7346, doi:10.1002/2016GL071941.

Garrett, T. J., and C. Zhao, 2006: Increased Arctic cloud longwave emissivity associated with pollution from mid-latitudes. $\mathrm{Na}$ ture, 440, 787-789, doi:10.1038/nature04636.

— M. M. Maestas, S. K. Krueger, and C. T. Schmidt, 2009: Acceleration by aerosol of a radiative-thermodynamic cloud feedback influencing Arctic surface warming. Geophys. Res. Lett., 36, L19804, doi:10.1029/2009GL040195.

Ghan, S. J., X. Liu, R. C. Easter, R. Zaveri, P. J. Rasch, J. H. Yoon, and B. Eaton, 2012: Toward a minimal representation of aerosols in climate models: Comparative decomposition of aerosol direct, semidirect, and indirect radiative forcing. J. Climate, 25, 6461-6476, doi:10.1175/JCLI-D-11-00650.1.

Hamilton, D. S., L. A. Lee, K. J. Pringle, C. L. Reddington, D. V. Spracklen, and K. S. Carslaw, 2014: Occurrence of pristine aerosol environments on a polluted planet. Proc. Natl. Acad. Sci. USA, 111, 18 466-18 471, doi:10.1073/pnas.1415440111.

Herman, G., and R. Goody, 1976: Formation and persistence of summertime Arctic stratus clouds. J. Atmos. Sci., 33, 1537-1553, doi:10.1175/1520-0469(1976)033<1537:FAPOSA > 2.0.CO;2.

Holland, M. M., and C. M. Bitz, 2003: Polar amplification of climate change in coupled models. Climate Dyn., 21, 221-232, doi:10.1007/s00382-003-0332-6.

— D. A. Bailey, B. P. Briegleb, B. Light, and E. Hunke, 2012: Improved sea ice shortwave radiation physics in CCSM4: The impact of melt ponds and aerosols on Arctic sea ice. J. Climate, 25, 1413-1430, doi:10.1175/JCLI-D-11-00078.1.

Jones, P. E., L. G. Anderson, and J. H. Swift, 1998: Distribution of Atlantic and Pacific water in the upper Arctic Ocean: Implications for circulation. Geophys. Res. Lett., 25, 765-768, doi:10.1029/98GL00464.

Kay, J. E., and A. Gettelman, 2009: Cloud influence on and response to seasonal Arctic sea ice loss. J. Geophys. Res., 114, D18204, doi:10.1029/2009JD011773.

_- M. M. Holland, C. M. Bitz, E. Blanchard-Wrigglesworth, A. Gettelman, A. Conley, and D. Bailey, 2012: The influence of local feedbacks and northward heat transport on the equilibrium Arctic climate response to increased greenhouse gas forcing. J. Climate, 25, 5433-5450, doi:10.1175/ JCLI-D-11-00622.1.

—, L. Bourdages, N. B. Miller, A. Morrison, V. Yettella, H. Chepfer, and B. Eaton, 2016: Evaluating and improving cloud phase in the Community Atmosphere Model version 5 using spaceborne lidar observations. J. Geophys. Res. Atmos. 121, 4162-4176, doi:10.1002/2015JD024699.

Kirtman, B., and Coauthors, 2013: Near-term climate change: Projections and predictability. Climate Change 2013: The Physical Science Basis, T. F. Stocker et al., Eds., Cambridge University Press, 953-1028.

Lamarque, J. F., and Coauthors, 2010: Historical (1850-2000) gridded anthropogenic and biomass burning emissions of reactive gases and aerosols: Methodology and application. Atmos. Chem. Phys., 10, 7017-7039, doi:10.5194/ acp-10-7017-2010.

Law, K. S., and Coauthors, 2014: Arctic air pollution: New insights from POLARCAT-IPY. Bull. Amer. Meteor. Soc., 95, 1873 1895, doi:10.1175/BAMS-D-13-00017.1.
Lee, J. E., A. Shen, B. Fox-Kemper, and Y. Ming, 2017: Hemispheric sea ice distribution sets the glacial tempo. Geophys. Res. Lett., 44, 1008-1014, doi:10.1002/2016GL071307.

Liu, X., and Coauthors, 2012: Toward a minimal representation of aerosols in climate models: Description and evaluation in the Community Atmosphere Model CAM5. Geosci. Model Dev., 5, 709-739, doi:10.5194/gmd-5-709-2012.

Lubin, D., and A. M. Vogelmann, 2006: A climatologically significant aerosol longwave indirect effect in the Arctic. Nature, 439, 453-456, doi:10.1038/nature04449.

Meinshausen, M., and Coauthors, 2011: The RCP greenhouse gas concentrations and their extensions from 1765 to 2300 . Climatic Change, 109, 213, https://doi.org/10.1007/s10584-011-0156-z.

Morrison, H., G. de Boer, G. Feingold, J. Harrington, M. D. Shupe, and K. Sulia, 2012: Resilience of persistent Arctic mixed-phase clouds. Nat. Geosci., 5, 11-17, doi:10.1038/ngeo1332.

Najafi, M. R., F. W. Zwiers, and N. P. Gillett, 2015: Attribution of Arctic temperature change to greenhouse-gas and aerosol influences. Nat. Climate Change, 5, 246-249, doi:10.1038/ nclimate2524.

Navarro, J. C. A., and Coauthors, 2016: Amplification of Arctic warming by past air pollution reductions in Europe. Nat. Geosci., 9, 277-281, doi:10.1038/ngeo2673.

Notz, D., and J. Stroeve, 2016: Observed Arctic sea-ice loss directly follows anthropogenic $\mathrm{CO}_{2}$ emission. Science, 354, 747-750, doi:10.1126/science.aag2345.

Overland, J. E., and M. Wang, 2013: When will the summer Arctic be nearly sea ice free? Geophys. Res. Lett., 40, 2097-2101, doi:10.1002/grl.50316.

Pithan, F., and T. Mauritsen, 2014: Arctic amplification dominated by temperature feedbacks in contemporary climate models. Nat. Geosci., 7, 181-184, doi:10.1038/ngeo2071.

Quinn, P. K., and Coauthors, 2015: AMAP Assessment 2015: Black carbon and ozone as Arctic climate forcers. Arctic Monitoring and Assessment Programme Rep., 128 pp.

Rigor, I. G., J. M. Wallace, and R. L. Colony, 2002: Response of sea ice to the Arctic Oscillation. J. Climate, 15, 2648-2663, doi:10.1175/1520-0442(2002)015<2648:ROSITT $>2.0$. CO;2.

Rosenfeld, D., and Coauthors, 2014: Global observations of aerosol-cloud-precipitation-climate interactions. Rev. Geophys., 52, 750-808, doi:10.1002/2013RG000441.

Rotstayn, L. D., and Coauthors, 2014: Declining aerosols in CMIP5 projections: Effects on atmospheric temperature structure and midlatitude jets. J. Climate, 27, 6960-6977, https://doi.org/ 10.1175/JCLI-D-14-00258.1.

Sand, M., T. K. Berntsen, Ø. Seland, and J. E. Kristjánsson, 2013a: Arctic surface temperature change to emissions of black carbon within Arctic or midlatitudes. J. Geophys. Res. Atmos., 118, 7788-7798, https://doi.org/10.1002/jgrd.50613.

, J. E. Kay, J. F. Lamarque, Ø. Seland, and A. Kirkevåg, 2013b: The Arctic response to remote and local forcing of black carbon. Atmos. Chem. Phys., 13, 211-224, doi:10.5194/ acp-13-211-2013.

-, K. von Salzen, M. G. Flanner, J. Langner, and D. G. Victor, 2015: Response of Arctic temperature to changes in emissions of short-lived climate forcers. Nat. Climate Change, 6, 286-289, doi:10.1038/nclimate2880.

Screen, J. A., and J. A. Francis, 2016: Contribution of sea-ice loss to Arctic amplification is regulated by Pacific Ocean decadal variability. Nat. Climate Change, 6, 856-860, doi:10.1038/nclimate3011. , and I. Simmonds, 2010: The central role of diminishing sea ice in recent Arctic temperature amplification. Nature, 464, 13341337, doi:10.1038/nature09051. 
Serreze, M. C., M. M. Holland, and J. Stroeve, 2007: Perspectives on the Arctic's shrinking sea-ice cover. Science, 315, 15331536, doi:10.1126/science.1139426.

Shindell, D., and G. Faluvegi, 2009: Climate response to regional radiative forcing during the twentieth century. Nat. Geosci., 2, 294-300, doi:10.1038/ngeo473.

Stohl, A., Z. Klimont, S. Eckhardt, K. Kupiainen, V. P. Shevchenko, V. M. Kopeikin, and A. N. Novigatsky, 2013: Black carbon in the Arctic: The underestimated role of gas flaring and residential combustion emissions. Atmos. Chem. Phys., 13, 88338855, doi:10.5194/acp-13-8833-2013.

Stroeve, J. C., V. Kattsov, A. Barrett, M. Serreze, T. Pavlova, M. Holland, and W. N. Meier, 2012: Trends in Arctic sea ice extent from CMIP5, CMIP3 and observations. Geophys. Res. Lett., 39, L16502, doi:10.1029/2012gl052676.

Taylor, P. C., M. Cai, A. Hu, J. Meehl, W. Washington, and G. J. Zhang, 2013: A decomposition of feedback contributions to polar warming amplification. J. Climate, 26, 7023-7043, doi:10.1175/JCLI-D-12-00696.1.

, S. Kato, K. M. Xu, and M. Cai, 2015: Covariance between Arctic sea ice and clouds within atmospheric state regimes at the satellite footprint level. J. Geophys. Res. Atmos., 120, 12 656-12 678, https://doi.org/10.1002/2015JD023520.

Walsh, J. E., F. Fetterer, J. S. Stewart, and W. L. Chapman, 2016: A database for depicting Arctic sea ice variations back to 1850. Geogr. Rev., 107, 89-107, https://doi.org/10.1111/j.1931-0846.2016.12195.x.
Wang, C., 2015: Anthropogenic aerosols and the distribution of past large-scale precipitation change. Geophys. Res. Lett., $\mathbf{4 2 ,}$ 10 876-10 884, doi:10.1002/2015GL066416.

Wang, H., and Coauthors, 2013: Sensitivity of remote aerosol distributions to representation of cloud-aerosol interactions in a global climate model. Geosci. Model Dev., 6, 765-782, doi:10.5194/gmd-6-765-2013.

Wang, Y., J. H. Jiang, and H. Su, 2015: Atmospheric responses to the redistribution of anthropogenic aerosols. J. Geophys. Res. Atmos., 120, 9625-9641, https://doi.org/10.1002/ 2015JD023665.

_ - P. L. Ma, J. H. Jiang, H. Su, and P. J. Rasch, 2016: Toward reconciling the influence of atmospheric aerosols and greenhouse gases on light precipitation changes in Eastern China. J. Geophys. Res. Atmos., 121, 5878-5887, https://doi.org/ 10.1002/2016JD024845.

_ - and Coauthors, 2017: The linkage between stratospheric water vapor and surface temperature in an observation-constrained coupled general circulation model. Climate Dyn., 48, 26712683, https://doi.org/10.1007/s00382-016-3231-3.

Xie, S.-P., B. Lu, and B. Xiang, 2013: Similar spatial patterns of climate responses to aerosol and greenhouse gas changes. Nat. Geosci., 6, 828-832, doi:10.1038/ngeo1931.

Zhao, C. F., and T. J. Garrett, 2015: Effects of Arctic haze on surface cloud radiative forcing. Geophys. Res. Lett., 42, 557564, doi:10.1002/2014GL062015. 